\title{
An Inactivated $P$. aeruginosa Immunomodulator Restores Imbalanced Epithelial Function Induced by In Vitro RSV Persistent Infection
}

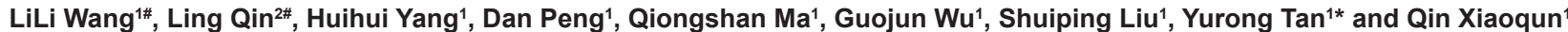

${ }^{1}$ Department of Basic Medicine, Xiangya School of Medicine, Central South University, China

${ }^{2}$ Department of Respiratory Medicine, Xiangya Hospital, Central South University, China

\#Equal Contribution

\begin{abstract}
Objectives: Previously, we observed that an inactivated $P$. aeruginosa vaccine (PPA) inhibited airway allergic inflammation by bronchial administration in an OVA-induced airway hyperresponsiveness animal model. To investigate the underlying mechanism involved, we studied the effects of PPA on epithelial functions in present studies by using an in vitro RSV persistent infection model.

Methods: Real-time PCR was used to examine RSV persistence. Real-time PCR and western blot were used to test the expressions of toll like receptor 4, IL-17A/Th2 signal molecules Act1 and NF-kB negative regulator A20 in BECs. Flow cytometry was used to observe the effects of PPA on cell proliferation and BECs-drived subsets' differentiation of CD4+T cells.

Results: PPA can stimulate toll like receptor-4 expression, promote cell proliferation in normal and RSV-infected BECs. PPA significantly increased Act1 and A20 expression in BECs inhibited by RSV infection. Also PPA inhibited Th2 and Th17 differentiation and stimulated Th1 differentiation induced by RSV infection.

Conclusions: Our data suggest that the therapeutic mechanism of PPA is partly due to promote bronchial proliferation and maintain the homeostasis of bronchial immunity.
\end{abstract}

Keywords: P. aeruginosa; Toll like receptors; RSV; CD4+T cells

\section{Introduction}

The incidence of diseases with airway hyperresponsiveness (AHR) such as chronic bronchitis, asthma and emphysema is increasing year by year, consuming a large amount of medical and economic resources. Diseases with AHR are complex inflammatory diseases usually characterized by imbalance of airway innate and adaptive immunity and airway chronic inflammation. Previously, we observed that the imbalanced airway immunity and airway chronic inflammation can be restored by the use of an inactivated $P$. aeruginosa vaccine (PPA) in an OVA-induced AHR animal model [1]. However, many factors can lead to AHR. Investigation of the effects of PPA under different conditions will contribute to a comprehensive understanding of the action of PPA in the airway protection.

Respiratory syncytial virus (RSV) is a member of the family $P$. aramyxoviridae, subfamily $P$. neumovirinae, which is the most common worldwide cause of epidemic respiratory diseases in children and bronchiolitis/pneumonia in infants, the elderly, and the immunocompromised. In addition to the acute manifestations of infection, RSV is thought to be associated with long-term complications, such as recurrent wheezing and asthma symptoms [2,3]. Virus culture and RT-PCR have confirmed that RSV mRNA existed in BALB/c mice lung tissue homogenate at least 100 days after RSV infection [4], indicating RSV persistence may be the main cause of airway chronic pathology, and ultimately AHR. Persistent RSV infections have been established in several human and animal epithelial cell lines [5] . In previous study, we have used BECs, a transformed human bronchial epithelial cell line, as an alternate approach for examining the molecular mechanisms of the in vitro progression of RSV infection under conditions that allow infection that occurs over four generations. When RSV at MOI $=0.01$ was used to infect BECs, the BECs survived to Generation 4. Surviving 16HBE cells in Generation (G2) showed similar healthy cell monolayer morphology as cultures of uninfected cells, while in G3 some small syncytia and irregularly shaped cells began to form and in G4 large syncytia were observed with decreased numbers of cells. G5 cultures were found to contain predominantly lysed cells (sumitted in other paper). G3 was chosen in present study.

P. aeruginosa is a common normal flora of the human body and a common pathogen of chronic infection of respiratory tract. Among pathogens in respiratory tract infection, gram-negative bacteria account for $77.3 \%$, in which $57.7 \%$ are $P$. aeruginosa. Based on whole animal experiments, using TLR knockout mice, the control of $P$. aeruginosa is believed to occur by the recognition of LPS and flagellin by TLRs 2,4 and 5 on airway epithelial cells, respectively [6,7]. Reduction of TLR4 expression in the bronchial epithelium may contribute to chronic bacterial infection of airways [8]. The adhesion portion of type 1 fimbria FimH from avian pathogenic E. coli strain can effectively activate TLR$4[9,10]$. So, we prepared an inactivated $P$. aeruginosa transfected with FimH (PPA) and observed its effect in AHR animal model in previous study. It was shown that PPA can decrease airway inflammation, improve epithelial functions and stimulate recovery from abnormal airway microenvironment; however, the precise mechanism remains unclear [1].

BECs play an important role in maintaining the homeostasis of

*Corresponding author: Yurong Tan, Department of Basic Medicine, Xiangya School of Medicine, Central South University, Changsha 410078, Hunan, China, Tel: 0086-731-82355003; E-mail: hope7@126.com

Received July 13, 2013; Accepted August 17, 2013; Published August 22, 2013

Citation: Wang L, Qin L, Yang H, Peng D, Ma Q, et al. (2013) An Inactivated $P$ aeruginosa Immunomodulator Restores Imbalanced Epithelial Function Induced by In Vitro RSV Persistent Infection. J Allergy Ther 4: 147. doi:10.4172/21556121.1000147

Copyright: (C) 2013 Wang L, et al. This is an open-access article distributed unde the terms of the Creative Commons Attribution License, which permits unrestricted use, distribution, and reproduction in any medium, provided the original author and source are credited. 
Citation: Wang L, Qin L, Yang H, Peng D, Ma Q, et al. (2013) An Inactivated P. aeruginosa Immunomodulator Restores Imbalanced Epithelial Function Induced by In Vitro RSV Persistent Infection. J Allergy Ther 4: 147. doi:10.4172/2155-6121.1000147

the respiratory system by providing a physiological barrier against the external milieu of the airway through the formation of tight junctions. Additionally, they contribute to host defense by producing cytokines, chemokines and other inflammatory mediators [11-13]. BECs are readily activated by superficial exposure to bacterial ligands and tolllike receptors (TLRs) mediate such responses. Several studies have shown that TLR-4 agonists can decrease allergic airway inflammation $[14,15]$ and mediate airway epithelial cells recognize endogenous harmful substances such as heat shock proteins, hyaluronic acid, degradation products, saturated and unsaturated fatty acids induced by ozone stress [16]. TLR- 4 mainly expresses in macrophages and epithelia [17]. Typically, BECs expresses a certain amount of TLR-4, but it decreases with age and many kinds of inflammatory diseases [18]. In present study, we focus on the effects and corresponding mechanism of PPA on immune imbalance and chronic inflammation induced by RSV persistence.

\section{Materials and Methods}

\section{Materials}

The inactivated $P$. aeruginosa transfected with type 1 fimbriae (PPA) was prepared by Beijing Wanteer Biological Pharmaceutical Co., Ltd. An inactivated $P$. aeruginosa without type 1 fimbriae was used as Control (PPAC). All antibodies were purchased from eBiosicence, USA unless otherwise stated. All primers were synthesized by In vitrogen, China.

\section{Preparation of RSV}

The strain A2 of human RSV was propagated in Hela cell monolayer grown at $37^{\circ} \mathrm{C}$ and $5 \% \mathrm{CO}_{2}$ enriched atmosphere in minimal essential medium supplemented with $2 \%$ heat-inactivated fetal bovine serum. At maximum cytopathic effect, the cells were repeatedly frozen and thawed to facilitate rupture. Next, the supernatants were harvested and cellular debris was removed by centrifugation. The RSV viral suspension was stored at $-80^{\circ} \mathrm{C}$

\section{Preparation of BECs and infection with RSV}

Human bronchial cell lines used in this study, the 16HBE14o-cells, were SV40-transformed human central airway epithelial cells. BECs were cultured in DMEM supplemented with $10 \% \mathrm{FBS}$ at $37^{\circ} \mathrm{C}$ under $5 \%$ $\mathrm{CO}_{2}$ in humidified air. $60-70 \%$ confluent monolayer cultures of BECs were infected with RSV at MOI of 0.01 according to experiments in advance. The virus was allowed to incubate for $2 \mathrm{~h}$ at $37^{\circ} \mathrm{C}$ in serumfree DMEM. Thereafter, non-absorbed virus was removed and washed two times, then the cells (the zero generation, G0) were cultured in fresh medium with $2 \%$ FBS and subcultured as needed. Cells were passaged two times per week. BECs treated by the same procedure from uninfected Hela cell lysate were used as a control. Control or BECs infected with RSV (G3) were added with $0.1 \mathrm{~mL}$ PPA $\left(2 \times 10^{7} \mathrm{pfu} / \mathrm{ml}\right)$ at $37^{\circ} \mathrm{C}$ for 24 hours before measurement.

\section{Assay of RSV infection in BECs}

RSV persistence was verified and monitored using a RSV Realtime PCR Kit (Huayin Medicine Biotechnology Co. Ltd., Guangzhou, China). This TaqMan ${ }^{\circledR}$-based real-time PCR kit includes the reagents for nucleic acid extraction, real-time PCR, high positive, and negative control materials. According to the instructions, the samples were considered negative for RSV when the threshold cycle number (CT) $>32.0$. Conservatively, samples with a CT value $\leq 28.9$ were considered clearly positive.

\section{Real-time PCR assay}

RNA was isolated and reverse transcribed into cDNA and analyzed by quantitative real-time PCR with SYBR Green I. The primers for TLR4 were 5'-GATGCTTCTTGCTGGCTGC-3 and 5'-ACCTTCATGGATGATGTTGGC-3'; for Act1 were 5' -AGTCAGCGAGCCTGCGTC-3' and 5'-CCATCTCCTGGCTACCGC-3'; for A20 were 5'-GGCAGGAAAACAGCGAGC-3' and 5'-GGCAGGAAAACAGCGAGC-3'. Briefly, $2 \mu \mathrm{l}$ (out of $20 \mu \mathrm{l}$ ) of the reverse-transcribed reaction mix was added to a $50 \mu \mathrm{l} \mathrm{PCR} \mathrm{mixture} \mathrm{for} 35$ cycles. Each cycle included $94^{\circ} \mathrm{C}$ for 20 seconds, $60^{\circ} \mathrm{C}$ for 30 seconds and $72^{\circ} \mathrm{C}$ for 30 seconds. Raw data were normalized to $\beta$-actin (5'-TGACGTGGACATCCGCAAAG-3' and 5'-CTGGAAGGTGGACAGCGAGG-3').

\section{Western blot analysis}

Control and RSV-infected BECs were lysed in protease inhibitor cocktail solution (Roche, Indianapolis, IN, USA). Cell lysates (70 $\mu \mathrm{g})$ were separated by SDS-PAGE and transferred to nitrocellulose membrane. The membrane were blocked with 3\% BSA in PBS for $2 \mathrm{~h}$ and then incubated with polyclonal rabbit anti Act I and A20 antibody at $4^{\circ} \mathrm{C}$ overnight and appropriate horseradish peroxidase-conjugated secondary antibody. Detection was made using the enhanced chemiluminescene system.

\section{Measurement of cell cycle by flow cytometry}

After being cultured in 6-well plates, cells were harvested at a density of $1 \times 10^{6} \mathrm{Cells} / \mathrm{mL}$, fixed in cold $70 \%$ ethanol and stored at $-20^{\circ} \mathrm{C}$ overnight. The fixed cells were washed twice with phosphate-buffered Saline, stained in a propidium iodide solution $(50 \mathrm{ug} / \mathrm{ml})$ for 1 hour, and treated with a ribonuclease A solution $(20 \mathrm{ug} / \mathrm{ml})$ for 30 minutes. Flow cytometry was then using to examine cell cycle.

\section{Co-culture of BECs and CD4+T cells}

In co-culture experiments, BECs were located at the bottom of the culture plate and the Jurkat E 6-1 Cells (CD4+T cells strain, a gift from Xiaojian Yao of Manitoba University) were suspended in culture medium. Non-infected and RSV-infected BECs were plated in 6-well culture plates with $2 \times 10^{6}$ cells/well. After BECs pretreated with PPA for $24 \mathrm{~h}$, Jurkat E 6-1 Cells were added to the BECs in a 1:1 ratio so that BECs and lymphocytes were cultured in the same well. After incubation at $37^{\circ} \mathrm{C}$ in $5 \% \mathrm{CO}_{2}$ for $48 \mathrm{~h}$, the lymphocytes were collected.

\section{Flow cytometric analysis of CD4+T cells subtypes}

Jurkat E 6-1 Cells were fixed with 4\% paraformaldehyde for $10 \mathrm{~min}$ at room temperature and permeabilized in permeabilizing solution (eBioscience, USA). After blocking with 3\% BSA for 15 min, cells were stained with appropriate anti- IL-4, IL-17 and IFN-gamma antibodies on ice for $45 \mathrm{~min}$. Isotype-matched antibodies were used as controls. The levels of antigen expression were expressed as a percentage of positive cells in the total cells.

\section{Statistical analysis}

Calculations were performed with SPSS software. All values were expressed as Mean \pm SE. Data were compared by use of the Student's t-test. $P$ value of less than 0.05 was considered significant.

\section{Results}

\section{Influences of PPA on TLR-4 expressions of BECs}

RSV persistence in BECs from G1 to G4 was confirmed by real-time 
Citation: Wang L, Qin L, Yang H, Peng D, Ma Q, et al. (2013) An Inactivated P. aeruginosa Immunomodulator Restores Imbalanced Epithelial Function Induced by In Vitro RSV Persistent Infection. J Allergy Ther 4: 147. doi:10.4172/2155-6121.1000147

PCR (Figure 1A). It was shown that RSV RNA progressively increased during successive passages. RSV RNA in BECs decreased after PPA and PPA treatment (Figure 1B). Next, we detected the expression of TLR-4 mRNA on BECs. The results showed that PPA stimulated TLR-4 expression in normal BECs in a dose-dependent manner (Figure $2 \mathrm{~A}$ ). According to this result, PPA with final concentration $2 \times 10^{6} \mathrm{cfu} / \mathrm{mL}$ was chosen to do subsequent experiments. It was shown that RSV had no influence on TLR-4 mRNA expression compared with normal BECs. TLR-4 expression substantially induced in PPA group and RSV plus PPA groups (Figure 2B).

\section{Influence of PPA on Act I or A20 expression of BECs}

As shown in Figure 3A it was found that RSV infection decreased the protein and mRNA expression of Act1.PPA increased the protein and mRNA expression of Act1 reduced by RSV infection. As shown in Figure 3B, it was found that RSV infection decreased the protein and mRNA expression of A20. PPA increased the protein and mRNA expression of A20 in normal and RSV-infected BECs.

\section{Influences of PPA on cell cycle of BECs}

To further examine the role of PPA on proliferation of BECs, we examined cell cycle of BECs by using flow cytometry. Results showed that the ratio of G1-phase in cells infected with RSV significantly increased, while S-phase significantly decreased when compared to normal BECs. PPA and PPAC significantly increased the numbers of S-phase cells in normal BECs and BECs plus RSV groups and PPA had a stronger effect on cell proliferation (Figure 4).
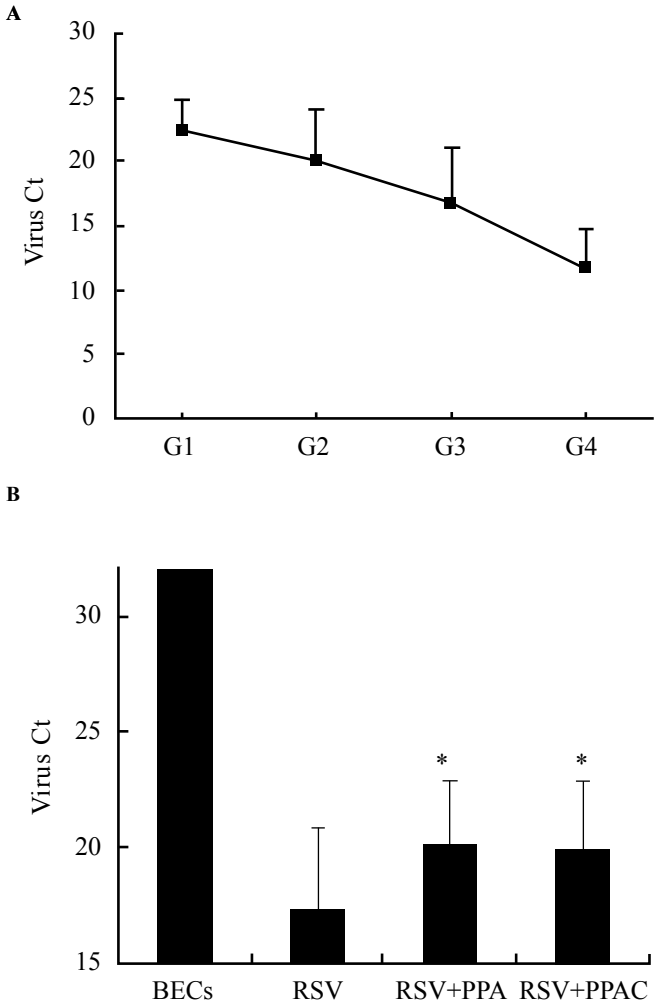

Figure 1: RSV RNA expression in surviving BECs. (A) RSV RNA levels during successive passages and (B) RSV RNA levels under different treatments. ( $\mathrm{MOI}=0.01 ;{ }^{*} \mathrm{P}<0.05$ versus normal $\left.\mathrm{BECs}\right)$.
A
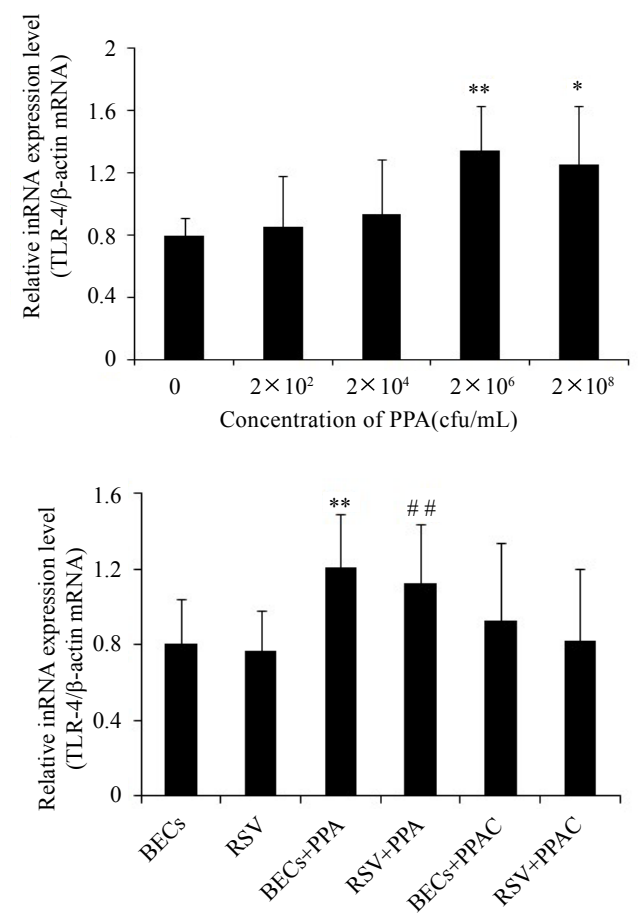

Figure 2: Human TLR-4 expression in BECs was determined by real time PCR. Data represent Means \pm SE of 4 experiments. $\left({ }^{* *} P<0.01\right.$ versus normal BECs; ${ }^{\#} P<0.01$ versus RSV).

\section{Influence of PPA on the distribution of Th subsets drived by BECs}

To further examine the role of PPA on the differentiation of Th subsets induced by BECs, we examined the distribution of Th subsets after co-culture with BECs. The results showed that Th2 and Th17 differentiation was induced, while IFN-gamma differentiation was suppressed in RSV-infected BECs. As expected, PPA stimulated Th1 differentiation and inhibited Th2 and Th17 differentiation drived by RSV infected BECs (Figure 5). PPAC only inhibited Th17 differentiation induced by RSV-infected BECs (Figure 5).

\section{Discussion}

BECs are not only an important barrier against the environmental injury factors, but also an active participant in a variety of acute and chronic inflammatory reactions in the airway. We established an in vitro model for infection of human BECs with RSV that persists for four generations prior to death at a multiplicity of infection $(\mathrm{MOI})=0.01$. In such a cell model above, we can observe the effects of PPA on the normal and chronic infected BECs.

BECs-derived signal molecules are very important in modulation of $\mathrm{T}$ cell responses. Recent studies showed that Act1 has two important functions. On one hand, Act1 is a key component in IL-17A signaling and induces Th2 differentiation [19]. On the other hand, it was recruited to CD40 and the TNF family member B cell-activating factor receptor in $B$ cells through its interaction with TNFR-associated factor, negatively regulates CD40- and BAFF-mediated B cell survival and reverses hypergammaglobulinemia and autoantibodies production [20]. Swaidani's research showed that epithelium-derived Actl has the essential role in allergic pulmonary inflammation through the 
Citation: Wang L, Qin L, Yang H, Peng D, Ma Q, et al. (2013) An Inactivated P. aeruginosa Immunomodulator Restores Imbalanced Epithelial Function Induced by In Vitro RSV Persistent Infection. J Allergy Ther 4: 147. doi:10.4172/2155-6121.1000147

Page 4 of 6
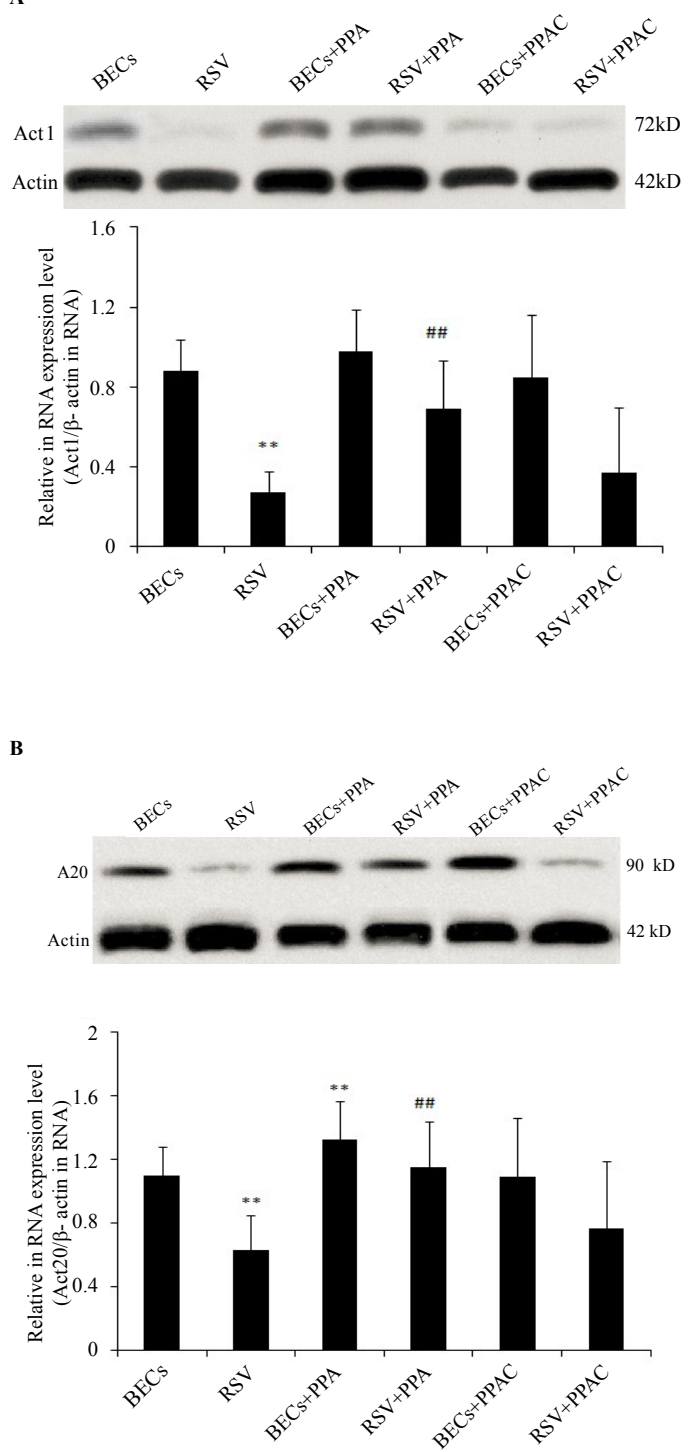

Figure 3: A: Human Act1 expression in BECs was determined by real time PCR and Western blot. B: Human A20 expression was determined by rea time PCR and Western blot. Data represent Means \pm SE of 4 experiments. $\left({ }^{* *} P<0.01\right.$ versus normal BECs; ${ }^{\#} P<0.01$ versus RSV).

distinct impact of the IL-17R-Act1 and IL-25R-Act1 axes and acts as a potential therapeutic target for allergic pulmonary inflammation [21]. In previous study, we observed that OVA stimulated the expression of Act1 and PPA significantly decreased its expression in BECs treated by OVA [1]. In present study, we observed RSV decreased the expression of Act1 and PPA significantly increased its expression in BECs infected by RSV, indicating that PPA has a very strong modulatory effect on homeostasis of signal molecule Act1.

A20, which is viewed as a potential therapeutic target for inflammatory diseases is an NF- $\kappa \mathrm{B}$-inducible protein and negatively regulates NF- $\kappa B$ signaling pathways [22]. PPA can significantly increase A20 expression in normal or RSV-infected BECs, indicating PPA is a hopeful therapeutic for airway inflammation by targeting NF$\kappa \mathrm{B}$ signaling pathway.

Proliferation and wound repair of BECs are recognized as an effective improvement of airway functions. In present study, we observed that $P$. aeruginosa had a very strong effect to stimulate cell proliferation of resting or RSV-infected BECs which may be related with a series of mechanisms such as they stimulate A20 expression which has strong effects on inhibiting cell apoptosis [23]; they accelerate wound repair in airway epithelial cells via a TLR-4-protein kinase C alphabeta-dual oxidase 1-reactive oxygen species-TACE-TGF-alphaEGFR phosphorylation pathway [24]; they accentuate TGF- $\beta 1$-driven epithelial-to-mesenchymal transition in the airway [25]; they may also have other ways to promote epithelial proliferation including the role of shielding to protect and promoting the release of epidermal growth factor [26]. PPA had a stronger effect on cell proliferation when compared with control $P$. aeruginosa.
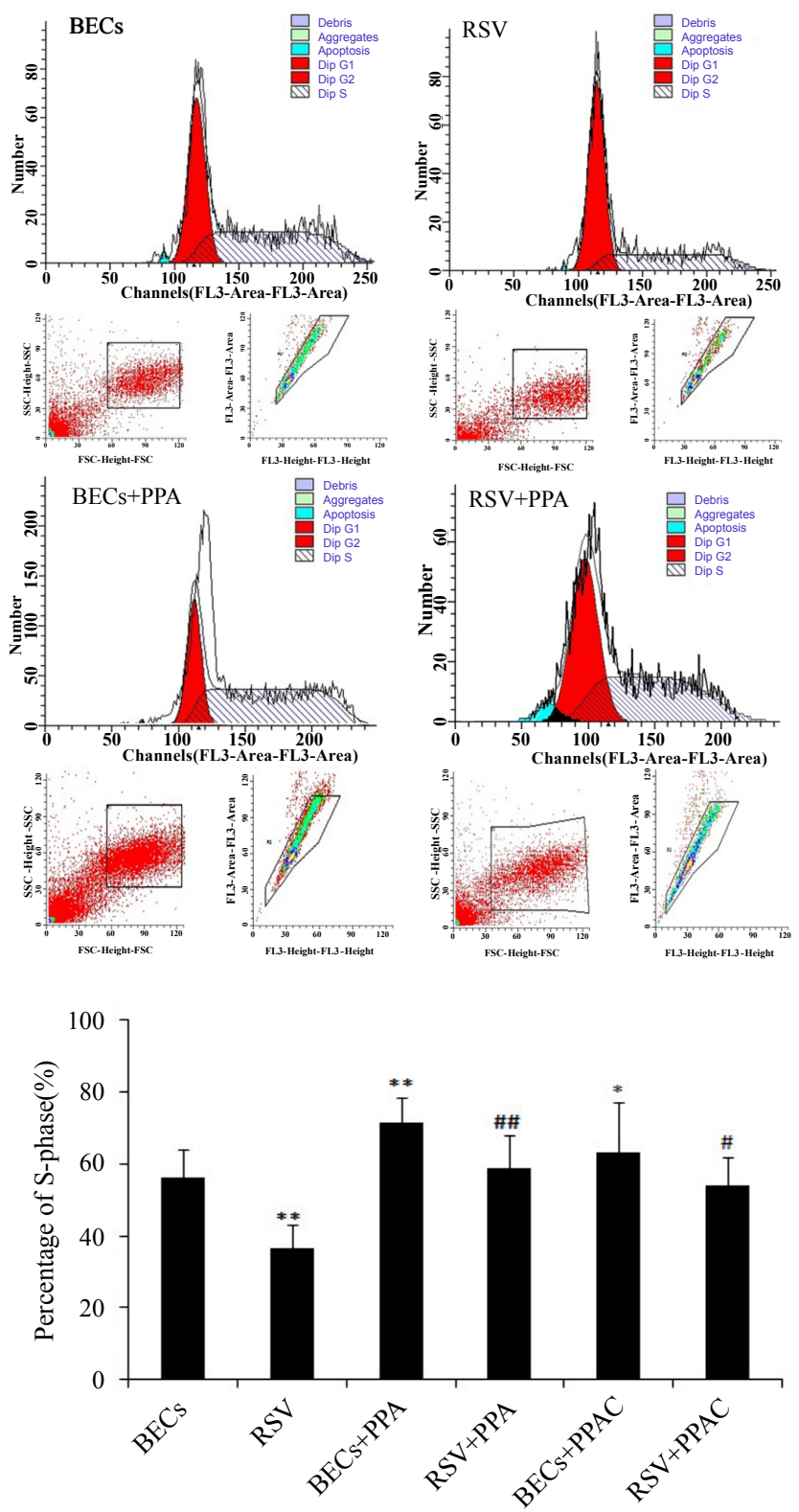

Figure 4: Effects of PPA on the cell cycle of BECs were assayed by flow cytometry. Data represent Means $\pm \mathrm{SE}$ of 6 experiments. ${ }^{*} P<0.05$ versus BECs; ${ }^{* *} P<0.01$ versus BECs; ${ }^{*} P<0.05$ versus RSV; ${ }^{\#} P<0.01$ versus RSV. 
Citation: Wang L, Qin L, Yang H, Peng D, Ma Q, et al. (2013) An Inactivated P. aeruginosa Immunomodulator Restores Imbalanced Epithelial Function Induced by In Vitro RSV Persistent Infection. J Allergy Ther 4: 147. doi:10.4172/2155-6121.1000147

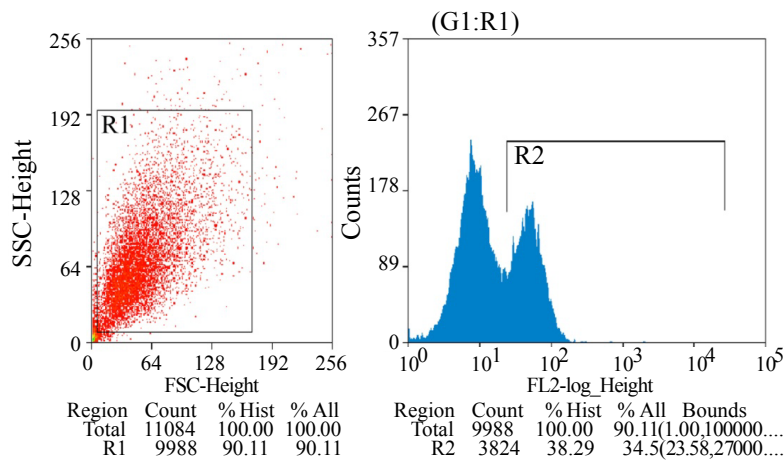

B

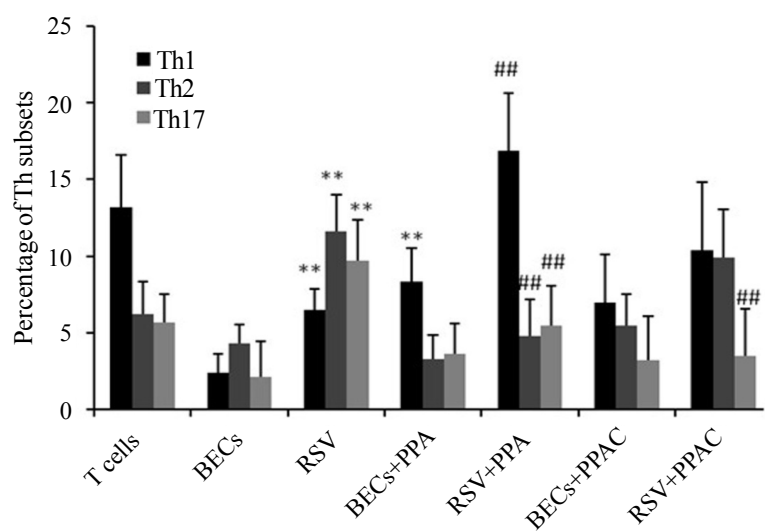

Figure 5: Effects of PPA on the change of Th subsets of CD4+ T cells. Data represent Means \pm SE of 10 experiments. ${ }^{* *} P<0.01$ versus BECs; ${ }^{\#} P<0.01$ versus RSV.

BECs are also one of important resources of $\mathrm{T}$ cell differentiation [27]. Through making use of TLRs that recognize conserved microbial structures, epithelial cells are able to sense microbes, which lead to the inducible secretion of further mediators and corresponding $\mathrm{T}$ cell differentiation [27] in our previous study. In present study, we observed PPA stimulated Th1 differentiation and inhibited Th2 and Th17 differentiation drived by RSV-infected BECs, indicating that PPA has a very strong modulatory effect on homeostasis of Th subsets.

Taken together, PPA can restore imbalanced $\mathrm{T}$ cell differentiation and stimulate proliferation and wound repair of BECs. These results might provide an opportunity for the development of novel therapeutics to treat airway diseases.

\section{Acknowledgements}

This work was supported by grants \#30870917, \#81170024, \#81100016, \#31100553, \#81270065 from National Natural Science Foundation of China; grants \#2009CB522102 and \#2012CB518104 from the National Basic Research Program of China (973 Program); grant \#NCET-10-0795 from New Century Excellent Talent Scheme of Ministry of Education, China; and grant \#2012QNZT111 from Young Teacher Fund of Central South University.

\section{References}

1. Tan Y, Liu H, Yang H, Wang L, Qin X (2013) An inactivated Pseudomonas aeruginosa medicament inhibits airway allergic inflammation and improves epithelial functions. J Physiol Sci 63: 63-69.

2. Bian T, Gibbs JD, Örvell C, Imani F (2012) Respiratory syncytial virus matrix protein induces lung epithelial cell cycle arrest through a p53 dependent pathway. PLoS One 7: e38052.

3. Remot A, Roux X, Dubuquoy C, Fix J, Bouet S, et al. (2012) Nucleoprotein nanostructures combined with adjuvants adapted to the neonatal immune context: a candidate mucosal RSV vaccine. PLoS One 7: e37722.

4. Schwarze J, O'Donnell DR, Rohwedder A, Openshaw PJ (2004) Latency and persistence of respiratory syncytial virus despite T cell immunity. Am J Respir Crit Care Med 169: 801-805.

5. Martinez I, Lombardia L, Herranz C, Garcia-Barreno B, Dominguez O, et al. (2009) Cultures of HEp-2 cells persistently infected by human respiratory syncytial virus differ in chemokine expression and resistance to apoptosis as compared to lytic infections of the same cell type. Virology 388: 31-41.

6. Raoust E, Balloy V, Garcia-Verdugo I, Touqui L, Ramphal R, et al. (2009) Pseudomonas aeruginosa LPS or flagellin are sufficient to activate TLRdependent signaling in murine alveolar macrophages and airway epithelial cells. PLoS One 4: e7259.

7. Descamps D, Le Gars M, Balloy V, Barbier D, Maschalidi S, et al. (2012) Tolllike receptor 5 (TLR5), IL-1 $\left.\right|^{2}$ secretion, and asparagine endopeptidase are critical factors for alveolar macrophage phagocytosis and bacterial killing. Proc Natl Acad Sci U S A 109: 1619-1624.

8. John G, Yildirim AO, Rubin BK, Gruenert DC, Henke MO (2010) TLR-4 mediated innate immunity is reduced in cystic fibrosis airway cells. Am J Respir Cell Mol Biol 42: 424-431.

9. Ashkar AA, Mossman KL, Coombes BK, Gyles CL, Mackenzie R (2008) FimH adhesin of type 1 fimbriae is a potent inducer of innate antimicrobial responses which requires TLR4 and type 1 interferon signalling. PLoS Pathog 4: e1000233.

10. da Silva Correia J, Ulevitch RJ (2002) MD-2 and TLR4 N-linked glycosylations are important for a functional lipopolysaccharide receptor. J Biol Chem 277 : 1845-1854.

11. Qu X, Li M, Liu HJ, Xiang Y, Tan Y, et al. (2013) Role of bombesin receptor activated protein in the antigen presentation by human bronchial epithelia cells. J Cell Biochem 114: 238-244.

12. Wang $Y$, Zhang $M$, Tan $Y$, Xiang $Y$, Liu $H$, et al (2007) BRS-3 activation transforms the effect of human bronchial epithelial cells from PGE2 mediated inhibition to TGF-beta1 dependent promotion on proliferation and collagen synthesis of lung fibroblasts. Cell Biol Int 31: 1495-1500.

13. Zhang JS, Tan YR, Xiang Y, Luo ZQ, Qin XQ (2006) Regulatory peptides modulate adhesion of polymorphonuclear leukocytes to bronchial epithelial cells through regulation of interleukins, ICAM-1 and NF-kappaB/lkappaB.Acta Biochim Biophys Sin (Shanghai) 38: 119-128.

4. Velasco G, Campo M, Manrique OJ, Bellou A, He H, et al. (2005) Toll-like receptor 4 or 2 agonists decrease allergic inflammation. Am J Respir Cell Mol Biol 32: 218-224

15. Chung SH, Choi SH, Cho KJ, Joo CK (2011) Toll-like receptor 4 signalling attenuates experimental allergic conjunctivitis. Clin Exp Immunol 164: 275-281.

16. Williams AS, Leung SY, Nath P, Khorasani NM, Bhavsar P, et al. (2007) Role of TLR2, TLR4, and MyD88 in murine ozone-induced airway hyperresponsiveness and neutrophilia. J Appl Physiol 103: 1189-1195

17. Wassef A, Janardhan K, Pearce JW, Singh B (2004) Toll-like receptor 4 in normal and inflamed lungs and other organs of pig, dog and cattle. Histo Histopathol 19: 1201-1208.

18. John G, Chillappagari S, Rubin BK, Gruenert DC, Henke MO (2011) Reduced surface toll-like receptor-4 expression and absent interferon- $\hat{I}^{3}$-inducible protein-10 induction in cystic fibrosis airway cells. Exp Lung Res 37: 319-326.

19. Claudio E, Sønder SU, Saret S, Carvalho G, Ramalingam TR, et al. (2009) The adaptor protein CIKS/Act1 is essential for IL-25-mediated allergic airway inflammation. J Immunol 182: 1617-1630.

20. Qian Y, Qin J, Cui G, Naramura M, Snow EC, et al. (2004) Act1, a negative regulator in CD40- and BAFF-mediated B cell survival. Immunity 21: 575-587.

21. Swaidani S, Bulek K, Kang Z, Liu C, Lu Y, et al. (2009) The critical role of epithelial-derived Act1 in IL-17- and IL-25-mediated pulmonary inflammation. J Immunol 182: 1631-1640.

22. Kang NI, Yoon HY, Lee YR, Won M, Chung MJ, et al. (2009) A20 attenuates allergic airway inflammation in mice. J Immunol 183: 1488-1495. 
Citation: Wang L, Qin L, Yang H, Peng D, Ma Q, et al. (2013) An Inactivated P. aeruginosa Immunomodulator Restores Imbalanced Epithelial Function Induced by In Vitro RSV Persistent Infection. J Allergy Ther 4: 147. doi:10.4172/2155-6121.1000147

23. Dong B, Lv G, Wang Q, Wei F, Bellail AC, et al. (2012) Targeting A20 enhances TRAIL-induced apoptosis in hepatocellular carcinoma cells. Biochem Biophys Res Commun 418: 433-438.

24. Koff JL, Shao MX, Kim S, Ueki IF, Nadel JA (2006) Pseudomonas lipopolysaccharide accelerates wound repair via activation of a novel epithelial cell signaling cascade. J Immunol 177: 8693-8700.

25. Borthwick LA, Sunny SS, Oliphant V, Perry J, Brodlie M, et al. (2011)
Pseudomonas aeruginosa accentuates epithelial-to-mesenchymal transition in the airway. Eur Respir J 37: 1237-1247.

26. Gao N, Kumar A, Jyot J, Yu FS (2010) Flagellin-induced corneal antimicrobial peptide production and wound repair involve a novel NF-kappaB-independent and EGFR-dependent pathway. PLoS One 5: e9351.

27. Qin L, Hu CP, Feng JT, Xia Q (2011) Activation of lymphocytes induced by bronchial epithelial cells with prolonged RSV infection. PLoS One 6: e27113. 